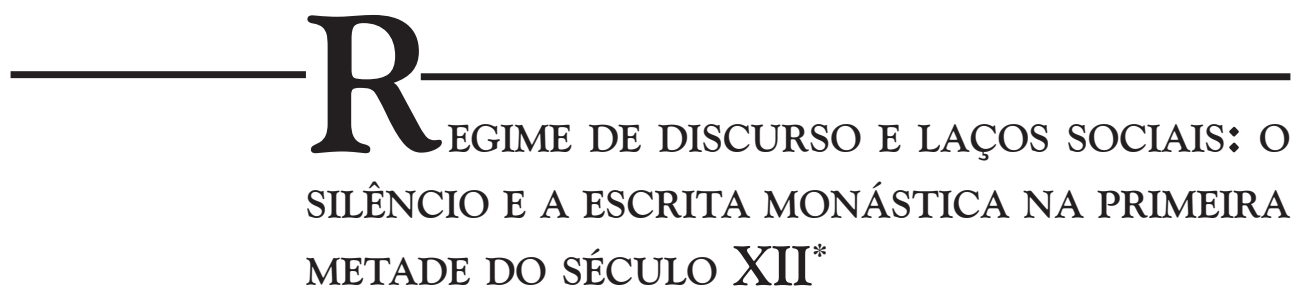

Gabriel de C. G. Castanho Universidade Federal do Rio de Janeiro - Rio de Janeiro Rio de Janeiro - Brasil

O presente artigo pretende estudar a participação dos profissionais da solidão (monges ou eremitas) na tessitura social da primeira metade do século XII na região da atual França. Quatro eixos argumentativos serão desenvolvidos em nosso percurso analítico. Iniciaremos por uma breve contextualização histórica destacando a relação dialética entre isolamento e organização social no período estudado, com especial atenção para a apresentação de nosso estudo de caso, o eremitismo monástico cartuxo. Em seguida, apresentarei, também brevemente, o conceito de "comunidade textual”, central para a argumentação que será aqui desenvolvida. Tal noção será colocada em relação com duas outras propriamente medievais e intrinsecamente ligadas ao contexto cartuxo: studium e propositum. A terceira etapa demonstrará como o cuidado com a escrita foi exercido na prática pelos monges cartuxos em sua comunicação com o mundo e durante a seleção de alguns de seus mais importantes manuscritos da primeira metade do século XII. Por fim, proponho que a função social do isolamento monástico no período, isto é, a pregação calada, constitui um "regime de discurso" ancorado na escrita e no silêncio e responsável por uma forma de sociabilidade ao mesmo tempo fundada no isolamento e inserida nas relações humanas. 


\section{O isolamento e a organização social}

\section{O "paradoxo" dos séculos XI e XII}

Há algumas décadas historiadores têm afirmado que a Europa dos séculos XI e XII foi marcada por um processo de expansão agrícola, comercial e urbano ${ }^{1}$. Impulsionada pelo chamado "período de aquecimento medieval" (nome dado às mudanças climáticas acontecidas entre os séculos X e XIV), tal expansão foi acompanhada, na documentação escrita, pela profusão de referências às relações sociais. É o caso, por exemplo, do aumento substancial de documentos notariais (cartas, diplomas, etc.) que testemunham os diferentes "contratos" ligando os homens entre si²; é o caso também da criação/renovação/reafirmação de igrejas, cemitérios e paróquias, vilas e outros quadros representativos da ancoragem territorial de comunidades (Iogna-Prat et Zadora-Rio 2005; Lauwers 2005; Mazel 2008). Assim, os séculos XI e XII teriam posto fim definitivo a um longo movimento socialmente centrífugo marcado pelo abandono das cidades e pela ruralização, ambos decorrentes do declínio do Império Romano. Se a importância dessa migração para o campo foi revista pelos medievalistas em função da descoberta de importantes continuidades políticas e econômicas em torno das civitates e das villae durante a Alta Idade $\mathrm{Média}^{3}$, pouco se atentou para o fato de que entre os anos 1050-1150 (ou seja, em pleno momento de fortalecimento dos laços sociais senhoriais e feudais) o ideal eremítico alimentou a busca pelo isolamento entre religiosos, mas também entre alguns leigos. É esse sincronismo paradoxal entre forças sociais centrípetas e centrífugas que pretendo abordar no presente artigo. Vejamos quais foram os principais aspectos dessa sincronia em um contexto preciso: o mundo eclesiástico.

Cronológica e tematicamente, encontramo-nos em pleno campo de batalha historiográfico. Tratar do eremitismo dos séculos XI e XII é flertar com os debates a propósito da existência e dos contornos do que se habituou chamar de "reforma gregoriana"4. No entanto, tal questão é secundária para os objetivos deste artigo, uma vez que parto do consenso geral de que, segundo temporalidades e interesses geopolíticos diferentes, muitos religiosos do período defenderam a prática eremítica e o isolamento como ideal a ser seguido neste mundo. De fato, um desejo de separação alimentou a importante onda eremítica iniciada nessa época (Centro di studi medioevali 1965; Université de Paris VIII 1995; Vauchez 2003). Os movimentos de "reformas" religiosas dos séculos XI e XII marcam assim um ponto de mudança importante no longo processo de controle social da solidão praticado pelos representantes da Igreja. Eles reforçaram a possibilidade de um isolamento espacial e espiritual vivido em comunidade, o que deu origem a uma formulação peculiar e hoje aparentemente 
contraditória: "sacer ordo eremiticus" (proferida pela chancelaria do papa Inocêncio II, em 1133, ao se dirigir aos cartuxos) (Bligny 1958:52).

A expressão papal sugere que a oposição entre o isolamento e a vida comunitária pode ser, no período, apenas superficialmente paradoxal. Uma das chaves para se compreender a dinâmica existente entre os termos pode ser encontrada no que se tem chamado de "polarização espacial". Conceito criado nos anos 1990 e largamente estudado nas últimas três décadas pela medievalística francesa, a "polarização" do espaço manifesta-se pela centralidade de um ponto para o qual converge toda uma cadeia de relações sociais e pela projeção do poder deste ponto sobre outros que dele dependem ${ }^{5}$. É o que observamos, nesse momento, no movimento de reorganização das comunidades de habitantes criadora de novos centros populacionais (Kuchenbuch, Scheler et Morsel 2005), mas também no distanciamento geográfico pretendido por monges e eremitas que participava da valorização da centralidade do lugar de culto no sistema eclesial. Nesse sentido, a fuga do mundo indica a existência de uma relação dialética muito rica entre a solidão e a vida em comunidade, e não uma simples contradição entre os termos. Os medievalistas devem, então, se dedicar a conhecer e a analisar as diferentes formas e dinâmicas dessa articulação.

O desejo pelo isolamento levado a cabo por eremitas e monges permitiu a criação de novos polos espaciais e, consequentemente, a criação de novas formas de relações entre os homens. Na vanguarda deste movimento encontramos as novas ordens monásticas surgidas a partir do século XI e que buscaram, mediante o isolamento social e geográfico, sua inserção na Igreja. Dentre elas, os cartuxos adquiriram grande notoriedade entre seus contemporâneos.

\section{Os cartuxos}

O mosteiro da Grande Cartuxa foi fundado em 1084 por Bruno de Colônia (c.1035-1101) e seus seis companheiros no maciço de mesmo nome (em um local chamado Casalibus). Segundo a documentação, o local era "inóspito" e "deserto" (Guigo I ${ }^{1889}: 15$ ), rapidamente entrando sob a proteção do bispo Hugo de Grenoble, o principal promotor secular da solidão cartuxa. Esse fundo de vale de forma triangular (semelhante a um isósceles), cercado por montanhas de mais de 1.300 metros de altura, dispunha de apenas uma fraca fonte de água. Em um dos ângulos, o menor dentre os três que formam o vale, situava-se a morada inicial de Bruno e seus eremitas, Casalibus; o lado oposto (ou seja, a base do triângulo) era delimitado por outra fronteira natural, a saber, um rio de bom volume correndo entre paredes rochosas e formando uma garganta de difícil travessia. Sem outros atrativos além da exígua área para pastoreio, o sítio era compatível com o desejo de isolamento dos religiosos. Separado do vilarejo mais próximo por mais de cinco quilômetros de caminhos tortuosos, o ermo cartuxo encontrava-se em uma região pré-alpina marcada pela baixa densidade populacional. Diferentemente da historiografia tradicional, prefiro o ter- 
mo "ermo" a "deserto" ao falar deste espaço de habitação cartuxo. Pretendo, assim, marcar o caráter relativo da separação social cartuxa: um distanciamento, mais do que um isolamento absoluto. Além disso, fato aparentemente simples ainda que não amplamente destacado pelos medievalistas, o termo "desertum" é de uso extremamente raro na documentação produzida pelos primeiros cartuxos, que optaram em seu lugar pelo vocábulo "heremus".

Às barreiras oriundas da geografia física do local de habitação escolhido por Bruno somava-se o que podemos chamar de "arquitetura de isolamento". Tal construção do espaço foi marcada, desde o início da Grande Cartuxa, pelo estabelecimento de uma casa baixa exclusivamente reservada para os "conversos" e de celas individuais para os monges (inspiradas no modelo da laura dos primeiros tempos do cristianismo) situadas originalmente a cerca de quatro quilômetros da primeira. Essa forma de ocupação do espaço mostra-nos que o isolamento cartuxo é, ao mesmo tempo, físico e institucional: os monges separam-se do mundo por meio de montanhas e rios; dos conversos, pela distância entre as respectivas casas; uns dos outros, por meio das celas individuais.

Após a avalanche de 1132 ter forçado a descida dos monges para um local mais seguro situado a cerca de dois quilômetros da casa baixa, foi preciso reforçar os instrumentos de isolamento. Nesse sentido, o desejo de espaço demograficamente vazio foi então reforçado e institucionalizado por bulas papais que proibiam a construção de novos prédios próximos aos limites do deserto cartuxo (Bligny 1975:148). A ocupação mais próxima será a casa dos irmãos conversos, situada a cerca de um quilômetro da ponte que dá acesso ao coração do ermo cartuxo. Além de responsáveis pela subsistência material da comunidade monástica, os leigos agiam também como uma espécie de porteiros da solidão.

No mosteiro propriamente dito, os religiosos viviam em celas individuais onde dispunham de uma pequena cozinha e de uma área de trabalho. Uma vez por semana ali recebiam alimentos a serem preparados e instrumentos necessários para o trabalho de cópia de manuscritos. Não havia na Grande Cartuxa um espaço comum, um scriptorium coletivo, onde os monges se reuniam para o trabalho com os textos (Guigo ${ }^{\circ}$ 1984, capítulo 28). Desse modo, evitava-se ao máximo o contato não apenas com as pessoas do século, mas também com outros monges da própria comunidade. De fato, as atividades que reuniam os religiosos eram apenas os ofícios e as refeições celebradas durante datas litúrgicas do magro calendário festivo cartuxo? ${ }^{7}$. Durante esses momentos, o controle das formas de comunicação verbais (Guigo I' 1984, capítulo 30, 1) e gestuais praticadas pelos monges era bastante estrito (Guigo Io 1984, capítulo 31, 3).

Distâncias quilométricas, montanhas, rio, casa baixa, celas pessoais, poucas ocasiões de encontro com outros religiosos; o controle da comunicação figura, assim, como o aspecto mais elementar e fundamental de uma sequência sobreposta de fronteiras visando ao isolamento. Contudo, como bem afirmou Catherine Santschi, "para os cartuxos, solidão não é isolamento" (Santschi 1995:31). Ou seja, é preciso levar em conta o aspecto relativo da solidão cartuxa tendo em vista que ela não é uma 
forma de isolamento total. A partir desse caráter polissêmico do isolamento religioso medieval, tenho defendido que a solidão é, no fundo, uma forma de relação social e não seu contrário. Ela é uma forma de comunhão que, como toda communio medieval, é simultaneamente comunicação social e mística. Mais especificamente, acredito que seja na dialética existente entre isolamento e contato social (sejam eles no campo material ou ideal da experiência humana) que a concepção cartuxa de solidão se cria. É, em suma, no seio desta dialética que a comunidade se funda e é nela também que os solitários encontram seu lugar dentro da instituição eclesiástica. Veremos a seguir como se dá essa relação a partir de um aspecto característico e de grande importância para a experiência religiosa dos monges cartuxos.

\section{A comunidade textual}

\section{O lugar do studium no propositum cartuxo}

Como os cartuxos puderam manter seus laços sociais sem abandonar o isolamento e a solidão? A resposta para essa importante questão encontra-se em uma das atividades capitais da vida monástica: a escrita. Como mostrou Brian Stock, as comunidades religiosas criaram suas identidades através da leitura de certos textos tidos como fonte de autoridade, assim como pela interpretação desses textos por outros membros de destaque dentro do grupo (Stock 1983). Dentre os primeiros monges cartuxos, Guigo Io (1083-1136) será a mais importante figura da comunidade textual cartuxa. Em torno de seus escritos, forjou-se a primeira identidade ou propositum cartuxo.

Entre 1121 e 1128, Guigo, o quinto prior da Grande Cartuxa, redigiu os Costumes praticados no mosteiro. Trata-se de documento de difícil enquadramento tipológico uma vez que não possui caráter propriamente diretivo (sua redação é resultado do pedido de casas monásticas que queriam conhecer os hábitos praticados na Grande Cartuxa), nem descritivo (para além de relatar a vida em seu mosteiro, Guigo detém o poder e o interesse de impor os costumes à sua comunidade), nem normativo (os destinatários dos Costumes não dependem da autoridade fundadora ou reformadora de Guigo) ${ }^{8}$. De todo modo, rapidamente o texto adquiriu valor normativo tanto na Cartuxa, quanto nas novas casas que foram criadas ou que aderiram ao modelo de vida ali exposto. Por cerca de uma geração ele foi praticamente a única referência em termos regulamentares dentro da nascente ordem cartuxa. Seja por seu caráter único, seja pela importância simbólica de seu autor (Guigo foi o responsável por garantir a inserção de sua comunidade no corpo mais amplo da Igreja ${ }^{9}$ ), os Costumes formam a coluna vertebral do projeto cartuxo de vida monástica. Ainda que se deva reconhecer a possível existência de uma distância entre a normatividade escrita e sua prática concreta, o maior legado do quinto prior da Grande Cartuxa foi estabelecer um propositum para seus monges-eremitas que fosse realizável aos olhos da comunidade, dos leigos e de outros membros do clero. 
Alguns anos após a morte de Guigo, o primeiro Capítulo geral das casas cartuxas foi convocado; contudo, tal encontro só se tornaria anual a partir de 1155 . Mesmo se a expressão "ordem cartuxa" já tivesse sido utilizada nos anos 1130 pelo papa, foi somente a partir dos anos 1150 que a Grande Cartuxa passou a ser considerada como mãe das demais casas cartuxas e detentora institucional de autoridade sobre elas. Momento de afirmação da centralidade de poder, os Capítulos surgiram em resposta a forças centrífugas que opunham dois partidos dentro da ordem nascente: "de um lado a Grande Cartuxa, Écouges e Durbon, e, de outro, Portes, Meyriat, Sylve-Bénite e Arvières"10. A eleição de um monge de Portes ao bispado de Grenoble colocava em risco a supremacia da casa mãe ${ }^{11}$. Para que um consenso fosse alcançado o Capítulo geral foi reforçado enquanto instância decisória superior.

O segundo quarto do século XII (entre a redação dos Costumes por Guigo I ${ }^{\circ}$ nos anos 1120 e o primeiro Capítulo geral anual em 1155) foi assim marcado pela tentativa de balancear o isolamento radical dos monges da Grande Cartuxa com o processo de nascimento de um ordo cartuxo. Foi somente ao final deste período original que se estabeleceu, na prática coletiva, uma rede de mosteiros dependentes da casa mãe. Em suma, o estudo desse período da história cartuxa revela-nos de maneira clara os limites institucionais mais extremos de um modelo de separação social amplamente reconhecido, valorizado pela Igreja e institucionalizado pela redação dos Costumes de Guigo e pelos estatutos dos capítulos gerais.

A busca pela adequação entre uma forma extrema de isolamento social e pela aceitação das normas capitulares gerais nos coloca novamente no caminho do propositum do grupo religioso aqui em questão. Tal como outros membros do clero na mesma época, os monges-eremitas não escapavam a uma das ordens do dia: a cura animarum. Sendo monges-padres, o modo pelo qual os cartuxos intercedem no mundo secular demonstra a tonalidade de seu propósito de isolamento social adequado a uma vida ativa no seio da Ecclesia.

De fato, encontramos, na relação de intercessão espiritual estabelecida pelos religiosos com os fiéis (sejam eles leigos, sejam eclesiásticos), alguns elementos importantes para a definição das diferenças entre modelos de solidão praticados no século XII. Sem levar em conta o fato de que muitos monges trocaram o isolamento do mosteiro pelo serviço dos altares nas catedrais, nós podemos resumir assim as especificidades do confronto entre a solidão e a rogatória em três grupos monásticos bastante diferentes durante a primeira metade do século XII. A riqueza litúrgica florescente em Cluny deve ser compreendida, em um sentido amplo, em conjunto com o poder polarizador do serviço dos mortos, e em um sentido preciso, com a valorização das orações in secreto dentro do perímetro da igreja. Entre os Grandmontanos, a pobreza conduz a exortação pelos atos, isto é, conduz a oferecer ao povo cristão um modelo de vida mais acessível, pois fundado na pobreza e no ideal de igualdade hierárquica entre monges e conversos, ambos pressupondo uma forma radical de abandono do mundo. 
Finalmente, os cartuxos pretendem cuidar da salvação dos outros por meio da escrita. Essa forma erudita de equilíbrio entre o isolamento e a ação no mundo é amplamente dependente da valorização cartuxa do studium. Tal prática (ao mesmo tempo mental, ascética e manual) é aqui profundamente marcada pela quietude e pelo silêncio, elementos comuns do propositum de separação dos monges face aos laicos e ao clero secular. Nesse sentido, Guigo definiu o studium e o propositum cartuxo como o ato de se dedicar constantemente ao silêncio e à solidão da cela, por oposição à abundância de missas cantadas entre os monges de outras vocações. De fato, o prior indica de modo bastante claro que a quietude, o isolamento e o silêncio são objetos dos studia para aqueles que buscam a paciência e a humildade, duas virtudes fundamentais no combate contra os vícios (Guigo Io 1984, capítulo 80, 7-8).

Vemos assim que o silêncio e a escrita necessários ao studium formam uma das bases principais do propositum cartuxo de abandono, mas, também, de ação neste mundo. Em torno desses elementos, Guigo constituirá sua comunidade textual concretizada pela redação dos Costumes, pela escolha e pela cópia dos primeiros textos que formarão o patrimônio comunal dos primeiros monges cartuxos.

\section{A cópia dos textos}

\section{A escolha dos textos}

Com a valorização da vida cenobítica levada a cabo pelos religiosos latinos entre os séculos IV e VI foi-se necessário estabelecer parâmetros para a organização coletiva da comunidade. Nesse período surgiram as primeiras traduções latinas de textos normativos monásticos orientais, com destaque especial para a regra de Basílio de Cesárea (330-379) trasladada por Rufino no final do século IV e as primeiras regras redigidas diretamente em latim, como a do Mestre $(500-530)^{12}$. Os autores desses textos manifestam preocupação constante com um dos erros mais comuns entre os religiosos que abraçaram a via contemplativa da salvação, a acedia. Um dos instrumentos mais utilizados nessa forma de combate espiritual foi o trabalho manual. Amplamente difundido por meio da Regra de São Bento (c.540, capítulo 48), o recurso às atividades físicas fazia-se ali de forma genérica, não se especificando quais atividades mereceriam a atenção dos religiosos. Foi ao longo dos séculos que a escrita, por meio da cópia de manuscritos, se impôs nos mosteiros como forma de afastar a preguiça. Tal progressão pode ser medida pela criação, difusão e ampliação de um espaço arquitetural, o scriptorium, durante a Alta Idade Média ${ }^{13}$. Ali eram produzidas cópias de textos fundamentais para a manutenção da vida religiosa, tais como a Bíblia e os tratados patrísticos. De fato, a reprodução de casas monásticas pressupõe paralelamente a (re)produção escrita dos preceitos que fundamentam o propositum cenobítico. Não é então por acaso que tais centros habitacionais passaram a produzir e a armazenar cópias de uma ampla variedade de testemunhos escritos (de tratados a 
atos notariais, de cartas a sermões, de coletâneas canônicas a vidas de santos, etc.). Muitos desses textos eram comumente encontrados em casas monásticas de diferentes naturezas, outros variavam de um local para outro segundo os interesses próprios de cada grupo ou da família espiritual da qual dependiam. Vejamos agora com mais detalhes alguns aspectos práticos do cuidado e da reprodução de textos escritos entre nossos monges-eremitas.

Os primeiros trinta anos do século XII foram marcados na Grande Cartuxa pela cópia de textos litúrgicos, jurídicos e biográficos - incluindo aí o Liber Pontificalis (até Estevão II, 752-757), os ensinamentos dos Pais da Igreja e de mestres cristãos da vida solitária. Com efeito, antes da avalanche de 1132 e do término da redação dos Costumes, os monges-eremitas já possuíam as Vitae Patrum, um homiliário próprio, um livro com 27 vidas de santos e a Bíblia de Nossa Senhora de Casalibus (Manuscritos 16-18 [1, 8, 3] da Biblioteca Municipal de Grenoble). Ali se encontravam também as Moralia in Iob de Gregório Magno, os comentários bíblicos de Jerônimo, os comentários sobre os Salmos de Agostinho e uma cópia das Falsas Decretais. Talvez do segundo quarto desse século sejam De praecepto et dispensatione, De gradibus humilitatis, Super Lucam, De diligendo Deo, de Bernardo de Claraval, e De virtute orandi, de Hugo de São Vitor. Excetuando-se a importância precoce atribuída às Vitae Patrum, a escolha dos textos é semelhante à praticada por outras ordens da mesma época, em especial Cister. No momento em que o isolamento geográfico era mais claro, proporcionado pela escolha do fundo de vale de Casalibus como local de moradia (e durante a redação dos Costumes), os monges procuraram testemunhar sua inserção na Igreja por meio de suas escolhas de textos a serem copiados e possuídos. Estes textos demonstram a vontade precoce por parte dos cartuxos de seguir os cânones da Igreja e de permanecer sob a influência papal.

\section{Uma atividade solitariamente coletiva}

Durante esse primeiro período de vida da ordem cartuxa, as pesquisas realizadas por Dominique Mielle de Becdelièvre puderam distinguir dezoito mãos diferentes, doze trabalhando na cópia da Bíblia de Nossa Senhora de Casalibus (sete copistas e cinco decoradores). Esse importante manuscrito foi redigido separadamente nas celas individuais dos monges (provavelmente doze no total). Os solitários encontravam-se assim literalmente inscritos em uma obra que de fato fundou o propositum da comunidade textual estabelecida no heremus. Momento fundador quando já se pode perceber a influência de Cluny no domínio paleográfico (Mielle de Becdelièvre 2004:147-148; sobre a tradição manuscrita dos primeiros cartuxos, ver também: Mielle de Becdelièvre 2000 e 2003, além de Vaillant et alii 1984).

No que concerne ao escopo deste artigo, são duas as principais marcas materiais da relação entre os primeiros cartuxos e seus livros: a prioridade dada à produção e à circulação de textos litúrgicos, assim como à cópia de coleções jurídicas; as influ- 
ências cluniacenses (paleográficas) e cistercienses (escolha das obras espirituais) são perceptíveis. A essa dupla característica deve-se somar uma terceira (a ser analisada mais abaixo): a escrita como instrumento privilegiado de trocas entre as casas monásticas e dessas com o mundo.

A análise codicológica e paleográfica demonstra que o pertencimento de cada um dos monges à comunidade mais ampla de fiéis (ou seja, à Igreja) se realizou por meio da reprodução de textos de grandes autoridades religiosas (tanto do passado, como do presente) e não pela produção de novos comentários exegéticos no ermo cartuxo (como será o caso dos escritos de Denis, o Cartuxo, já no contexto de forte urbanização das práticas religiosas em meados do século XV). Esta é a forma característica pela qual os primeiros cartuxos acreditavam pertencer a um grupo social mais largo materializado pelos manuscritos que guardavam na solidão, uma atividade de reprodução textual que se manifestava até mesmo pela imitação das técnicas de escrita já estabelecidas no seio da Igreja. Os cartuxos visavam assim pertencer a uma comunidade textual já existente, trazendo a ela uma contribuição sutilmente reformadora manifestada pela uniformização do ductus da escrita (e, consequentemente, de sua caligrafia), pela simplicidade dos ornamentos e pela temática espiritual privilegiada.

Nossos monges-eremitas encontram, através da escrita, sua própria maneira de equilibrar a geografia física e a topografia subjetiva da solidão. Nesse sentido, o fato de que a primeira grande obra copiada na Grande Cartuxa tenha sido a Bíblia de Casalibus, realizada ainda antes de 1132, não é algo sem importância, uma vez que o trabalho realizado individualmente nas celas inscrevia cada monge em uma comunidade mais ampla. Contudo, o centro desta assembleia de fiéis encontra-se no ermo, o que implica em uma concepção eclesiológica substancialmente diferente da produzida por outros membros do clero (secular ou regular) ${ }^{14}$. Para reforçar a inserção dessa microcomunidade no cosmos social representado pela Igreja, o quinto prior cartuxo trabalhou ainda na distinção crítica entre textos falsos e verdadeiros que pertenciam até então à tradição cristã - como foi o caso do estudo das cartas de Jerônimo realizado por Guigo (Egan 1999). Em suma, o estudo da primeira comunidade cartuxa, instalada num fundo de vale, demonstra que a solidão produz, ela também, discursos e práticas sociais que circulam bem além do ermo e participam na constituição dos laços sociais existentes entre os homens do período.

\section{A pregação pelas mãos}

\section{A comunhão cartuxa per litteras}

A síntese apresentada pela primeira comunidade textual cartuxa reunida ao redor de Guigo Io para o "paradoxo" evocado no início deste artigo e marcado pela sincronia histórica entre os fenômenos sociais de polarização espacial e de fuga do mundo fica agora mais clara. A conciliação entre isolamento e ação no mundo levam 
os cartuxos a apoiar uma forma específica de equilíbrio entre esses dois aspectos fundamentais da religiosidade no século XII: manibus predicatio (a pregação pelas mãos). De fato, essa prática permite que os cartuxos assegurem seu pertencimento à Igreja, apesar do isolamento geográfico em que vivem. No capítulo 28 dos Costumes, Guigo diz: "Nós queremos que os livros sejam feitos com toda a dedicação [studiosissime] e guardados com grande cuidado, como um alimento perene de nossas almas, para que preguemos por nossas mãos as palavras de Deus, uma vez que nós não o podemos fazer com nossas bocas" (Guigo I ${ }^{\circ}$ 1984:224, tradução nossa, grifo nosso) ${ }^{15}$.

A pregação pelas mãos é, assim, no plano das práticas, o testemunho mais evidente do modo como os cartuxos pretendem participar da Igreja - uma sociedade que se constitui, em grande medida, per litteras, como afirma Guigo em uma carta dirigida ao grande mestre dos Templários em 1128: "Pois, como [durante o caminho] de ida e de retorno, nós não pudemos desfrutar de vossa presença agradabilíssima, nos pareceu [bom] dialogar convosco, pelo menos um pouco, por meio da escrita" (Guigo $I^{\circ} 1962: 154$, tradução nossa) ${ }^{16}$. O prior deixa claro nessa correspondência a forma de interação a ser estabelecida com aqueles que vivem para além das fronteiras de seu ermo: a exortação ao abandono do mundo (de seus vícios) mesmo para aqueles que nele vivem ${ }^{17}$.

A mesma posição explica, de forma implícita, mas com consequências práticas de grande importância, o fato de que Guigo, tendo feito votos de se dedicar ao ermo (como consta na fórmula de tomada do hábito cartuxo expresso no capítulo 23 dos Costumes $^{18}$ ), buscou reiteradas vezes se comunicar com figuras de grande envergadura de seu tempo. Suas cartas são testemunhos de que o prior pretendia exercer um papel de relevo nos rumos tomados pela Ecclesia, sem que para isso tivesse que abandonar a estabilidade de seu ermo, pelo contrário.

Em uma carta destinada ao papa Inocêncio II e lida no concílio de Reims em 1131, Guigo ataca os cismáticos que se opõem "à paz e à verdade católica"19. A tomada de partido durante o chamado cisma de Anacleto em prol de Inocêncio II confirma o pertencimento dos monges-eremitas a uma comunidade mais ampla ${ }^{20}$. Comunidade e não multitudo, uma vez que, em oposição a essa última, a ordenação do isolamento social confirma, junto ao papa, o papel da solidão na Igreja. Ainda durante o mesmo cisma, Guigo demonstra que seu horizonte vai além da instituição eclesiástica ao se dirigir a Guilherme X, duque da Aquitânia e partidário de Anacleto II da contenda. Partindo de uma premissa eclesiológica que vê na Ecclesia não apenas um corpo de ministros, mas também a totalidade da assembleia de fiéis, o prior busca participar da ampliação da comunidade e da fé (duas faces da mesma moeda) a partir do ermo ${ }^{21}$. Tomando o exemplo bíblico do dilúvio, o prior afirma que fora da arca transfigurada na comunidade de fiéis (ecclesia), ninguém poderia escapar da morte espiritual ${ }^{22}$.

Com outra tonalidade, mas ainda partindo da articulação entre ermo e Igreja, Guigo envia uma carta ao cardeal Aimeric que havia visitado a Grande Cartuxa entre 1132 e 1134 . Vê-se nesta ocasião que nem a distância poderia romper a co- 
munhão existente entre o ermo e Roma; apenas os vícios podem separá-los ${ }^{23}$. É para evitar tal rompimento que a carta foi redigida visando instruir o cardeal a levar uma vida de isolamento, mesmo entre as paredes do palácio papal. $\mathrm{O}$ argumento do prior constrói-se sobre oposições como pobreza e avareza, jejuns e glutonia, humildade e orgulho para afirmar a existência de uma comunhão espiritual calcada em uma comunidade moral que transcende o espaço físico ${ }^{24}$. Ao final dessa comunicação escrita percebemos que a comunidade se encontra simultaneamente no mundo exterior e no mundo interior dos homens ${ }^{25}$.

Em outra carta redigida para o clero secular, datada de 1133, Guigo comunica-se com o concílio de Jouarre para instigar naquela assembleia a defesa do bem público e do bem privado colocados em risco após o assassinato do prior de São Vitor de Paris ${ }^{26}$. Distante centenas de quilômetros do local dos fatos e, ao que tudo indica, sem jamais ter conhecido a vítima, o quinto prior da Grande Cartuxa defende que, por meio do ataque a um de seus membros, foi na verdade a comunidade espiritual a real vítima, o que colocaria em risco o bom equilíbrio social entre os fiéis. Tal linha de pensamento se assenta sobre um pressuposto estreitamente ligado à concepção de comunhão social e de fé subjacente aos textos analisados até aqui: para melhor preencher sua função, a Igreja, como responsável pela proteção daqueles que vivem no tumulto do século, deve disciplinar a comunidade, tal como um abade ou prior o faz com sua congregação.

Para concluir a presente articulação analítica entre as chamadas comunidades espiritual e textual, cabe apresentar uma importante carta de Pedro, o Venerável, abade de Cluny entre 1122 e 1156, destinada a Guigo. Por meio dessa comunicação tomamos conhecimento de que Pedro buscava obter, junto aos cartuxos, algumas cópias críticas das Cartas de Santo Agostinho a São Jerônimo. De seu lado, os monges-eremitas buscavam obter, entre outros, um manuscrito do Contra Cassiano de Prospéro de Aquitânia ${ }^{27}$. Essas trocas per litteras entre o ermo e o mundo demonstram que os cartuxos se interessavam também pela constituição dogmática da comunidade de fiéis manifestada pela vontade de Guigo em possuir apenas cópias fiáveis dos escritos religiosos (Egan 1999). A eclesiologia mística de Guigo I fica, assim, cada vez mais clara ao levarmos em conta a escrita como ação no mundo e, consequentemente, seu par dialético, o silêncio no ermo. Trata-se de um regime de discurso composto, tal como a música, por sons e pausas caladas, mas com fortes implicações sociais. A noção de regime que proponho aqui tem em comum com a de ordem do discurso proposta por Michel Foucault em 1970 (Foucault 1971) o fato de pensar as múltiplas formas de expressão como algo construído historicamente em função de contextos socioculturais específicos, mas visa, sobretudo, valorizar o papel dialético de governança desempenhado por uma multidão de formas de comunicação, mesmo aquelas modalidades que parecem (a princípio) se opor a esse gênero de relação social, como o silêncio.

Pode-se dizer, em suma, que, mediante uma construção ativa (por meio da prática escrita) da comunidade espiritual, os cartuxos, sem abandonar a solidão, pre- 
tendiam nada menos que assumir um papel de vanguarda na sociedade cristã, ou seja, na ecclesia. Nesse contexto, a escrita, atividade que concretiza o propositum cartuxo, é resultado dos studia, ou seja, dos cuidados espirituais e intelectuais dependentes do isolamento físico tão caros aos monges-eremitas. De tudo isso pode-se concluir que o estabelecimento de uma identidade grupal centrada no zelo para com a escrita (comunidade textual) alimenta a formação de uma comunidade de espírito desejada pelos cartuxos e projetada para além do ermo.

\section{Regime de discurso e isolamento: silêncio, escrita e sociedade}

Antes de encerrarmos o presente artigo, cabe dizer, a título provocativo para pesquisas futuras, que a articulação cartuxa entre silêncio, escrita e pregação, embora tenha contornos específicos, não deve ser tomada como algo único e exclusivo. $\mathrm{O}$ caso cluniacense já citado algumas vezes ao longo deste artigo pode aqui servir de exemplo. Sob a pluma de Pedro, o Venerável, o silêncio assume um sentido eclesiológico de grande envergadura quando associado aos combates contra os heréticos, os judeus e os sarracenos (Iogna-Prat 1998). A modalidade de silêncio reforçada pelos estatutos cluniacenses está profundamente ligada ao que foi chamado de "pastoral do livro", isto é, a escrita como suporte privilegiado para o exercício monástico da cura animarum (Iogna-Prat 1997; Henriet 2000:217-218).

Tomar a palavra com o objetivo de abordar alguns temas espirituais chave é, ao mesmo tempo, salutar e necessário (incontornável em boa medida, como vimos no caso das cartas de Guigo) para a reprodução do tecido social entre os anos 10501150. É nesse contexto geral que Pedro, o Venerável escreve sobre a ideia aparentemente paradoxal de um taciturnus praedicator, ou seja, de um orador qualificado pela ausência de palavras ${ }^{28}$. A partir do princípio espiritual que articula o silêncio à escrita, o abade de Cluny, assim como Guigo $I^{\circ}$, faz dessas duas práticas instrumentos monásticos por excelência no combate levado a cabo tanto pelos monges que vivem isolados em seus mosteiros, como por aqueles religiosos que, mesmo vivendo sob uma regra, atuam junto aos assuntos mundanos.

Ao final de nosso percurso uma nova linha de pesquisa abre-se aos medievalistas preocupados com uma compreensão sistêmica do "paradoxo" sincrônico estabelecido entre os fenômenos de polarização espacial e de abandono do mundo evocados na abertura deste artigo. A articulação entre isolamento e silêncio, de um lado, e, de outro, entre ação no mundo e escrita oferece uma via renovada de análise social a partir de um regime de discurso fundado na solidão, mas concretamente interessado na Ecclesia. A pregação e o cuidado com as almas dos fiéis, elementos capitais da religiosidade dos séculos XI-XII, interligam dialeticamente esses dois pontos duplos, 
dando origem a uma eclesiologia que visa ora silenciar, ora utilizar as palavras dos fiéis em função de sua utilidade e eficácia (material e espiritual) não apenas para os indivíduos, mas para a sociedade como um todo. Pregando pelas mãos, o orador taciturno abandona o século para poder melhor agir nele.

\section{Referências Bibliográficas}

BLIGNY, Bernard (ed.). (1958), Recueil des plus anciens actes de la Grande-Chartreuse (1084-1196). Grenoble: [s.n.].

BLIGNY, Bernard. (1975), "Les Chartreux dans la société occidentale du XII e siècle”. Cahiers d'histoire: publiés par les Universités de Lyon, Grenoble, Clermont-Ferrand, Saint-Étienne, Chambéry, n 20, vol. 2: 137-166.

CASTANHO, Gabriel. (2015), "Por uma sociologia da solidão medieval: isolamento, sociedade e religião em contexto normativo monástico (mundo latino, séculos IV-XII)”. Revista Signum, vol. 16: 196-214. Disponível em: http://www.abrem.org.br/revistasignum/index.php/revistasignumn11/article/view/166/155. Acesso em: 01/2016.

CENTRO DI STUDI MEDIOEVALI. (1965), L'eremitismo in occidente nei secoli XI e XII, Atti della settimana di Studio, Mendola, 1962. Milão: Vita e Pensiero.

CONSTABLE, Giles (ed.). (1967), The letters of Peter the Venerable. Cambridge: Harvard University Press, vol. 1.

COWDREY, Herbert. (1993), "The carthusians and their contemporary world: The evidence of the twelfth-century bishops' Vitæ”. In: Die Kartäuser und ihre Welt. Kontakte und gegenseitige Einflüsse: internationaler Kongress vom 23. Bis 26. September 1992, vol. 1. Salzbourg: Institut für Anglistik und Amerikanistik.

DAVRIL, Anselme. (2005), "Coutumiers directifs et coutumiers descriptifs d'Ulrich à Bernard de Cluny". In: S. Boynton et I. Cochelin (orgs.). From Dead of Night to End of Day: The Medieval Customs of Cluny/Du cœur de la nuit à la fin du jour: Les coutumes clunisiennes au Moyen Âge. Turnhout: Brepols.

DUBOIS, Jacques. (1968), "Quelques problèmes de l'histoire de l'ordre des Chartreux à propos de livres récents”. Revue d'Histoire Ecclésiastique, n 63: 27-54.

. (1986), "Les institutions monastiques au XII siècle. À propos des coutumes de Chartreuse rédigées par Guigues et éditées par un Chartreux". Revue d'histoire de l'Église de France, n 72, vol. 189: 209-244.

DUBY, Georges. (1978), Guerreiros e camponeses. Os primórdios do crescimento económico europeu. Lisboa: Estampa.

EGAN, Belinda. (1999), "The Carthusians and the Textual Uniformity”. In: J. Hogg, A. Girard e D. Le Blévec (orgs.). Los Cartujos en Andalucía. Salzbourg: Institut für Anglistik und Amerikanistik, vol. 1.

FOUCAULT, Michel. (1971), Lordre du discours: leçon inaugurale au Collège de France prononcée le 2 décembre 1970. Paris: Gallimard.

GRANDJEAN, Michel. (1994), Laïcs dans l'Église: Regards de Pierre Damien, Anselme de Cantorbéry et Yves de Chartres. Paris: Beauchesne.

GUERREAU, Alain. (1996). "Quelques caractères spécifiques de l'espace féodal européen". In: N. Bulst, R. Descimon et A. Guerreau (orgs.). LÉtat ou le roi. Les fondations de la modernité monarchique en France (XIV -XVII siècles). Paris: Maison des sciences de l'homme.

. (2002), "Il significato dei luoghi nell'Occidente medievale: struttura e dinamica di uno ‘spazio' specifico”. In: E. Castelnuovo e G. Sergi (orgs.). Arti e storia nel Medioevo. I. Tempi, Spazi, Istituzioni. Turim: G. Einaudi. 
(2003), "Structure et évolution des représentations de l'espace dans le haut Moyen Âge occidental”. In: Uomo e spazio nell'alto Medioevo. Spoleto: Centro di studio sull'alto Medioevo. GUIGO I. (1889), "Vita sancti Hugonis episcopi gratianopolitani (BHL 4016)”. In: C. Bellet. Guigues I. Vita S.Hugonis episcopi Gratianopolitani. Montreuil-sur-Mer: Typis Cartusiae Sanctae Mariae de Pratis.

. (1962), Lettres des premiers Chartreux I: s. Bruno, Guigues, s. Anthelme [ed., introd., trad. e notas por um cartuxo, M. Laporte]. Paris: Cerf. te]. Paris: Cerf.

(1984), Coutumes de Chartreuse [ed., introd., trad. e notas por um cartuxo, M. Lapor-

GUYOTJEANNIN, Olivier; PYCKE, Jacques; TOCK, Benôit-Michel (orgs.). (2006), Diplomatique médiévale. Turnhout: Brepols, $3^{\mathrm{a}} \mathrm{ed}$.

HENRIET, Patrick. (2000), La parole et la prière au Moyen Âge. Le verbe efficace dans l'hagiographie monastique des XI ${ }^{e}$ et XII ${ }^{e}$ siècles. Bruxelas: DeBoeck.

IOGNA-PRAT, Dominique, et ZADORA-RIO, Élizabeth (orgs.). (2005), La paroisse. Genèse d'une forme territoriale. Revue Médiévales, $\mathrm{n}^{\circ} 49$.

IOGNA-PRAT, Dominique. (1997), "Limpossible silence: Pierre le Vénérable, neuvième abbé de Cluny (1122-1156) et la pastorale du livre”. In: R. M. Dessi et M. Lauwers (orgs.). La parole du prédicateur ( $V^{E}-X V^{E}$ siècle). Nice: Z’éditions.

. (1998), Ordonner et exclure. Cluny et la société chrétienne face à l'hérésie, au judaïsme et à l'islam (1000-1150). Paris: Aubier.

KUCHENBUCH, Ludolf; SCHELER, Dieter; et MORSEL, Joseph (orgs.). (2005), La formation des communautés d'habitants au Moyen Âge. Perspectives historiographiques, table ronde de Xanten (R.F.A.), les 19-22 juin 2003, Paris: LAMOP. Disponível em: http://lamop.univ-paris1.fr/spip.php?article471. Acesso em: 03/05/2015.

LAUWERS, Michel. (2005), Naissance du cimetière. Lieux sacrés et terre des morts dans l'Occident médiéval. Paris: Aubier.

. (2014), "Mosteiros, lugares de vida e espaço social: sobre a construção dos complexos monásticos no Ocidente Medieval”. Territórios e Fronteiras, n 7, vol. 2: 4-31. Disponível em http:// www.ppghis.com/territorios\&fronteiras/index.php/v03n02/article/view/344. Acesso em: 01/2016.

LECLERCQ, Jean et ROCHAIS, Henri (eds.). (1977), Epistolae. Roma: Editiones Cistercienses (S. Bernardi Opera, VIII).

LUNVEN, Anne. (2014), Du diocèse à la paroisse. Évêchés de Rennes, Dol et Alet/Saint-Malo (VE-XIII ${ }^{e}$ siècle). Rennes: PUR.

MANUSCRITOS 16-18 $(1,8,3)$ da Biblioteca Municipal de Grenoble (Bible de Notre-Dame de Casalibus). Disponível em: http://manuscrits-medievaux.bm-grenoble.fr/. Acesso em: 03/05/2015.

MAZEL, Florian (org.). (2008), L'espace du diocèse. Genèse d'un territoire dans l'Occident médiéval (Ve-XIII siècle). Rennes: PUR.

louse: Privat.

MEHU, Didier. (2001), Paix et communautés autour de l'Abbaye de Cluny: Xe-XVe siècle. Lyon: PUL.

MIELLE DE BECDELIÈVRE, Dominique. (2000), "Une enquête sur le fonds cartusien du XII siècle de la bibliothèque municipale de Grenoble”. In: R. Combra et G. Merlo (orgs.). Certosini e cistercensi in Italia (secoli XII-XV). Cuneo: Societè per gli storici, archeologici ed artistici della provincia di Cuneo..

. (2003), "La tradition de la lecture et la première bibliothèque cartusienne (fin XI - début XII siècle)”. In: A. Girard, D. Le Blevec, et N. Nabert (orgs.). Saint Bruno et sa postérité spirituelle. Salzbourg: Institut für Anglistik und Amerikanistik.

. (2004), Prêcher en silence: enquête codicologique sur les manuscrits du XII siècle provenant de la Grande Chartreuse. Saint-Étienne: PUSE.

REVUE D'HISTOIRE DE L'ÉGLISE DE FRANCE. (2010), Revue d'Histoire de l'Église de France, tome 96. 
RUST, Leandro e SILVA, Andréia. (2009), "A Reforma Gregoriana: trajetórias historiográficas de um conceito". História da Historiografia, vol. 3: 135-152.

RUST, Leandro. (2013), A reforma papal (1050-1150). Cuiabá: Ed. UFMT.

SANTSCHI, Catherine. (1995), "La solitude des ermites. Enquête en milieu alpin”. Revue Médiévales, $\mathrm{n}^{\circ}$ 28: 25-40.

STOCK, Brian. (1983), The Implications of Literacy: Written Language and Models of Interpretation in the Eleventh and Twelfth Centuries. Princeton: University Press.

UNIVERSITÉ DE PARIS VIII. (1995), Le choix de la solitude. Revue Médiévales, nº 28.

VAILLANT, Pierre et alii. (1984), Les manuscrits de la Grande Chartreuse et leurs enluminures. Grenoble: Roissard.

VAUCHEZ, André (dir.). (2003), Ermites de France et d'Italie (XI'-XVé siècle) Roma: EFR.

ZUMTHOR, Paul. (1993), La mesure du monde : représentation de l'espace au Moyen Âge. Paris: Seuil.

\section{Notas}

* A presente pesquisa foi realizada com financiamento da CAPES por meio de uma bolsa de Doutorado Pleno no exterior desenvolvido na Universidade de Paris 1 e na EHESS (Paris) entre os anos de 2009 e 2013.

1 Ainda que tenham sido regional e cronologicamente nuançadas, as teses de Georges Duby a respeito do desenvolvimento socioeconômico europeu durante a chamada Idade Média central continuam válidas quando comparadas ao período anterior. Ver Duby (1978).

2 Sobre o desenvolvimento da produção diplomática no período, ver Guyotjeannin, Pycke et Tock (2006).

3 Contrariamente ao que antes se acreditou, a continuidade administrativa em civitates e em villae existiu mesmo em uma região relativamente pouco romanizada, como demonstrou recentemente Lunven (2014).

4 Para um balanço atual da questão, ver Mazel (2013) e também o número consagrado ao mesmo tema publicado no tomo 96 da Revue d'histoire de l'Église de France (2010). Para uma visão crítica da ideia de "reforma gregoriana", ver Rust e Silva (2009) e Rust (2013).

5 Zumthor (1993) foi o primeiro a empregar esta noção que, em seguida, foi desenvolvida por Guerreau (1996, 2002, 2003). Para um desenvolvimento prático da questão, ver Mehu (2001).

6 A primeira metade do século XII viu a expansão do uso desse tipo de mão de obra laica, especialmente entre as chamadas novas ordens monásticas. Os conversos eram fundamentalmente responsáveis pela produção e pela troca de bens necessários à subsistência dos religiosos. Para uma crítica à noção de conversos empregada por medievalistas, ver Dubois (1968:37).

7 Como exemplo, ver o capítulo sobre as celebrações dominicais, dia de atividades coletivas da comunidade (Guigo I 1984, capítulo 7)

8 Sobre essa tríade tipológica dos costumes medievais, ver Davril (2005, tradução nossa) - diretivos: "costumes que objetivam fixar por escrito os hábitos vivos de um mosteiro em um determinado momento de sua existência [...] trata-se de documentos escritos em um mosteiro para uso interno e destinados a fixar um hábito existente" (:23); descritivos: "hábitos de certo mosteiro sem que o redator tenha a vontade ou a possibilidade de os impor" (:24); normativos: "costumes destinados a fixar um modo de vida, na maioria das vezes para o transmitir à outra casa monástica, seja ela uma nova fundação em busca de regra, ou um mosteiro que se pretende reformar dando-lhe um costume testado e considerado como melhor" (:24).

9 Foi na primeira metade do século XII que importantes figuras do clero contemporâneo, como o papa Adriano IV, Guilbert de Nogent, Bernardo de Claraval e Pedro, o Venerável, viram nos cartuxos um exemplo de perfeito equilíbrio entre os ideais eremíticos e cenobíticos. 
${ }^{10}$ Pedro, o Venerável, ep. 158a, ao papa Eugênio III (1150-1151), no original: "Divisa inter se, et quae usque ad haec tempora specialius aliis unum in Christo fuerat, hac de causa inuicem congregatio sancta compugnat. Hinc Cartusia, Excubiae, Durborum, hinc Portae, Mioreuum, Silua, Aluerium, et si qua sunt alia ad sacrum illum ordinem pertinentia loca, uelut diuersos parietes statuunt, et tam hi quam illi se iuxta prophetam pro domo Israel ascendere ex aduerso, et stare in praelio in die domini profitentur [Ez. 13, 5]" (Constable 1967:378). Ver também a carta 149, a Bernardo de Claraval, datada de 1149 (Constable 1967:363-366). Para um breve balanço histórico da questão, ver Dubois (1986:231-232). Para a posição de Bernardo de Claraval a respeito dessas disputas, ver Leclercq et Rochais (1977): Bernardo ep. 250, ao prior de Portes 1150-1151 (:145-147); Bernardo, ep. 270, ao papa Eugênio III, em 1151 (:178-180); e, finalmente, Bernardo, ep. 389, a Pedro, o Venerável em 1149 (:356-357).

${ }^{11}$ Sobre a nomeação de monges cartuxos como bispos, ver Cowdrey (1993).

12 Sobre o processo de normalização do isolamento, ver Castanho (2015).

13 Para uma visão de conjunto da evolução histórico-arquitetural dos mosteiros, ver Lauwers (2014).

${ }^{14}$ Cerca de um século antes, com Pedro Damiano (1007-1072), encontramos uma visão semelhante da centralidade do ermo no sistema eclesial medieval (Grandjean 1994).

${ }^{15}$ No original: "Libros quippe tanquam sempiternum animarum nostrarum cibum cautissime custodiri et studiosissime volumus fieri ut quia ore non possumus, dei verbum manibus predicemus." (Guigo I 1984, capítulo 28, 3).

${ }^{16}$ No original ad Hugonem sanctae militiae priorem: "Quoniam in revertendo, sicut in veniendo, praesentiae vestrae gratissima allocutione frui nequivimus, visum est nobis ut per litteras vobiscum saltem pauca colloqueremur." (Guigo I 1962:154).

${ }^{17}$ No original ad Hugonem sanctae militiae priorem: "Frustra quippe exteriores hostes impetimus, si non prius intimos superamus. [...] Acquiramus itaque, dilectissimi, prius nosmetipsos, ut secure deinceps ad externos pugnemus inimicos; mentes nostras prius a vitiis, dehinc terras purgemus a barbaris." (Guigo I 1962:154).

${ }^{18}$ No original: "Ego frater ille, promitto stabilitatem et obedientiam, et conversionem morum meorum, coram deo et sanctis eius, et reliquiis istius heremi, quae constructa est ad honorem dei et beatae semper virginis mariae et beati iohannis baptistae, in presentia domni illius prioris +" (Guigo I 1984, capítulo 23, 1).

${ }^{19}$ No original ad Innocentem papam: "Engolismensem videlicet Gerardum, nisi veternosa cupiditas et ambitio diabolicis immissa suggestionibus, contra catholicam pacem et veritatem tam impudenter tamque pertinaciter ire coegit?" (Guigo I 1962:168).

${ }^{20}$ No origjnal ad Innocentem papam: "vestrae Majestatis pedibus advoluti, pro cunctis quidem, sed maxime pro novellis Religionibus, Cisterciensi scilicet ac Fontebraldensi, necnon pro universo mundo preces offerimus. Non enim pars una, sed totus potius est orbis vestra diocesis" (Guigo I 1962:168).

${ }^{21}$ No original ad Willelmum ducem aquitanorum: "Spiritus Sanctus [...] per eosdem prophetas ecclesiam tanquam sponsam et corpus ipsius toto dilatandam orbe praedixit” (Guigo I 1962:176).

${ }^{22}$ No original ad Willelmum ducem aquitanorum: "Ab hac itaque Ecclesia a prophetis praedicta, ab apostolis plantata, martyrum, beatorum et confessorum laboribus aucta et totum per orbem dilatata, quae sola corpus est Christi, sola vivit de Spiritu Christi, quicumque, occasione quacumque, recedit, frustra sibi de qualibet religione blanditur, frustra de quantacumque potestate confidit, postremo frustra de ipso christiano nomine gloriatur, quia, sicut extram arcam in diluvio nulla potuit caro salvari, sic extra Ecclesiam a morte perpetua nemo poterit liberari" (Guigo I 1962:178).

${ }^{23}$ No original ad Aimericum cardinalem: "A quo solo summo et benefico bono, societate scilicet et visione Dei, non spatiis locorum aut temporis - semper enim est et ubique, et in ipso vivimus, movemur et sumus [Act. 17, 28] - sed meritis sejungimur peccatorum" (Guigo I 1962:184).

${ }^{24}$ No original ad Aimericum cardinalem: "Quanto enim melius ecclesiae palatiis leges, quam palatia darent ecclesiis! [...] Quanto utilis ipsi nostram paupertas, nostra jejunia susciperent atque humilitatem, quam nos eorum avaritias, delicias, atque elationem?" (Guigo I 1962:190). 
${ }^{25}$ No original: "Habetote, quaesumus, domum istam in mente vestra, sicut ipsa vos reclusit in sua" (Guigo I 1962:194).

${ }^{26}$ No original ad jotrense concilium: "Etsi igtur beati Thomae et ceterorum qui recenter lotis in Sanguine Agni stolis suis ad coelestia demigrarunt, in conspectu Domini mors pretiosa mundana ultione no egeat, tamen, quia periculosum est si Ecclesia Dei, sine qua nec publicae res salvae sunt, nec privatae, utilitate tamen careat disciplinae, rogamus supplices et obsecramus, quatenus armatura fidei protecti, et rectitudinis zelo succensi [...] in sacrilegos homicidas ecclesiastici rigoris intrepide gladium producatis, eosque, si fieri potest, omnibus sacrorum officiis perpetuo privetis ac beneficiis" (Guigo ${ }^{\circ}$ 1962:200, 202).

${ }^{27}$ Pedro, o Venerável, ep. 25, c.1136, no original: "Prosperum contra Cassianum sicut nostis non habemus, sed pro eo ad sanctum Iohannem Angeliacesem in Aquitania misimus, et iterum si necesse fuerit mittemus" (Constable 1967:47).

${ }^{28}$ A expressão aparece na carta 20 de Pedro, o Venerável, destinada a Gilbert, no original: "Sic plane sic uerbi diuini poteris fieri taciturnus praedicator, et lingua silente, in multorum populorum auribus manus tua clamosis uocibus personabit" (Constable 1967:38-39).

Recebido em maio de 2015. Aprovado em janeiro de 2016.

Gabriel de C. G. Castanho (gabrielcgc@terra.com.br) Professor do Instituto de História e do Programa de Pós-Graduação em História Social da Universidade Federal do Rio de Janeiro. Doutor em História e Civilizações pela Escola de Altos Estudos em Ciências Sociais (EHESS), Paris, França. 


\section{Resumo:}

\section{Regime de discurso e laços sociais: o silêncio e a escrita monástica na pri- meira metade do século XII}

Momento de importante expansão urbana e econômica, o século XII foi também marcado por vozes que clamavam pelos desertos europeus. Social e religiosamente, esse foi um tempo marcado pela tensão entre a reestruturação da vida em comunidade e a valorização do isolamento eremítico. $\mathrm{O}$ aparecimento dos monges cartuxos (talvez a mais importante ordem eremítica medieval), ocorrido nesse contexto, oferece uma ocasião privilegiada para o estudo do que venho chamando de "monopólio da solidão" (o controle do isolamento pela Ecclesia). Pretendo aqui demonstrar como a escrita e o silêncio (ligados ao studium e à noção de comunicação "per litteras") constituem um verdadeiro "regime de discurso" responsável por solucionar dialeticamente a contradição existente entre o propositum eremítico de abandono do mundo e sua inserção na comunidade eclesial.

Palavras-chave: Idade Média, Monasticismo, Grande Cartuxa, Solidão, Eclesiologia.

\section{Abstract:}

Regime of speech and social bonds: the monastic silence and writing in the first half of the 12th century

Moment of a major urban and economic expansion, the twelfth century was also marked by voices crying from the European deserts. This was a time marked by the tension between a reorganization of the community life and the search for isolation. The appearance of the Carthusian monks occurred precisely at this context. It offers a major opportunity for a closer study of ecclesial process that I have called "the monopolization of loneliness" (the control of isolation by the Ecclesia). I intend to demonstrate how writing and silence (linked to the studium and the notion of communication "per litteras") constitute a true "regime of speech" dialectically responsible for solving the contradiction between the hermit propositum abandonment of the world and their insertion on the ecclesial community.

Keywords: Middle Ages, Monasticism, Grande Chartreuse, Solitude, Ecclesiology. 